\title{
Perspectives
}

\section{Mediterranean Diet conceptual model and future trends of its use in Portugal}

\author{
Helena Real ${ }^{1,2, *}$, Rui Rosa Dias ${ }^{3,4}$, and Pedro Graça ${ }^{2}$
}

${ }^{1}$ Associação Portuguesa de Nutrição, Rua João das Regras, n. ${ }^{\circ} 284$ R/3 e n. ${ }^{\circ} 278$, Porto 4000-291, Portugal, ${ }^{2}$ Faculdade de Ciências da Nutrição e Alimentação da Universidade do Porto, Rua Dr. Roberto Frias, Porto 4200-465, Portugal, ${ }^{3}$ IPAM, Instituto Português de Marketing - Porto, Rua Manuel Pinto de Azevedo, 748, Porto 4100-320, Portugal and ${ }^{4}$ Universidade Europeia, Rua Laura Ayres, n. ${ }^{\circ}$, Lisboa 1600 510 , Portugal

*Corresponding author. E-mail: helenamaiareal@gmail.com

\section{Summary}

The aim of this study was to present a new model for the Mediterranean Diet definition and to identify the major trends for the use of the Mediterranean Diet concept by 2028, in Portugal. A Delphi panel was implemented with 28 experts with solid knowledge and understanding of the Mediterranean Diet concept. The first round evaluated the degree of expert self-knowledge, which also contributed to the final questionnaire building. It was answered in 2 successive rounds with 21 statements, divided into 2 dimensions: Mediterranean Diet concept and use. A Mediterranean Diet model definition was produced with $73.8 \%$ of agreement. Culture, education, environment, health, food industry/distribution and tourism were identified as the future trends of Mediterranean Diet use areas. The model presented can be used as a pedagogical tool. For the first time, it was possible to explore the future trends of Mediterranean Diet use, which can help with the initiatives to safeguard the Mediterranean Diet concept.

Key words: Mediterranean Diet conceptual map, Delphi, Mediterranean Diet, trends

\section{INTRODUCTION}

A recent publication of the EAT-Lancet Commission on healthy diets from sustainable food systems highlighted the importance of the relation between food, environment and health (Willett et al., 2019). Nowadays, we are in the Anthropocene, 'a geological epoch that is characterized by humanity being the dominating driver of change on Earth' (Willett et al., 2019) and it is important to promote the discussion about strategies that can improve the food systems and the population diets to provide for the growing world population. Another aspect that marks the current world agenda is the Sustainable Development Goals, adopted by all United Nations Member States in 2015 (United Nations, 2015). It represents 17 Sustainable Development Goals mainly about people, the planet, peace, prosperity and partnership (United Nations, 2015).

The Mediterranean Diet can be part of the strategy to respond to both situations identified above, because it represents a very well-studied cultural model, with a positive impact on health, in the environment preservation, and cohesion between people. The distinction awarded to the Mediterranean Diet as an Intangible Cultural Heritage of 
Humanity by the United Nations Educational, Scientific and Cultural Organization (UNESCO, 2013a) initiated a new era of opportunities for this concept. Simultaneously, other areas beyond health, began to emerge in the Mediterranean Diet panorama (Real and Graça, 2019). One of the operational directives for the implementation of the Convention for the Safeguarding of the Intangible Heritage is precisely the framework with Sustainable Development Goals (UNESCO, 2018) and the Mediterranean Diet fits well within it.

In spite of its great recognition, studies show that there is a tendency of decreased adhesion in the countries of the Mediterranean (Vilarnau et al., 2019). In Portugal, the values of adhesion to the Mediterranean food pattern are $\sim 18 \%$, so, not very high (Lopes et al., 2017).

In 2013, along with the inscription in UNESCO, Portugal created the follow-up group for the Safeguarding and Promotion of the Mediterranean Diet $(71 / 2014,2014)$, that was responsible for various missions and activities, in which the Mediterranean Diet promotion would be highlighted. Later, in 2018, the Competence Centre for the Mediterranean Diet (Centro de Competências para a Dieta Mediterrânica, 2018) and in 2019 the Council for the Safeguarding and Promotion of the Mediterranean Diet (Despacho n. ${ }^{\circ} 1939 / 2019,2019$ ) were created. The main objective of all these groups is the promotion and the safeguard of the Mediterranean Diet. However, it is hard to be successful if the Mediterranean Diet definition is diffuse or very complex, which complicates the information transmission to the population and the safeguard of the correct model. Currently, the consensual Mediterranean Diet definition is the one proposed by UNESCO (UNESCO, 2013a), but it is very extensive and complex. The Mediterranean Diet Safeguarding Plan for the Algarve area for 2018 - 21 is in application, in Portugal (Comunidade Representativa de Tavira, 2018) and the trend identification of the Mediterranean Diet concept use may contribute to the discussion involved in the construction of the next one.

In 2017, the authors of this paper began a study with some experts from the Algarve region in Portugal, about the concept perceptions, with the aim of building an adequate and easily transmitted Mediterranean Diet definition. Now, it is important to expand the discussion about this issue and to understand if the proposed model could be used in the future as a tool to promote the Mediterranean Diet. One of the best ways to identify future trends is through the application of a Delphi approach (Hsu and Sandford, 2007; Geist, 2010; James and Warren-Forward, 2015), which will be the methodological basis of the present work. Therefore, the constitution of a Delphi panel that promotes the discussion on the trends of the Mediterranean Diet concept use, in the next 10 years, is another aim of this research.

To our best knowledge there is no other study in this area in Portugal, which can help in the development of initiatives and strategies to prepare for the future, and ensure that the concept is correctly used over the years, and prevent it from being lost or misrepresented for the next generations.

\section{OBJECTIVES}

The objective of this research was to develop a new model for the Mediterranean Diet definition and try to identify the major trends for the Mediterranean Diet concept use over the long term: 2028, in Portugal.

\section{METHODOLOGY}

\section{Delphi survey implementation}

The Delphi method is a technique that can structure a group communication process and it is effective in allowing a group of experts, as a whole, to deal with a complex problem (Linstone and Turoff, 1975). It represents a consensus-building technique that allows different stakeholders to be integrated into a process of successive evaluations construction, without external influences or biases, obtained from pre-designed questionnaires. It represents a simple, efficient and economical model of obtaining a convergence of opinions on future trends of a certain area that could represent the basis for the development of projections, recommendations and for the creation of more solid policies and intervention programs (Hsu and Sandford, 2007; Geist, 2010; James and Warren-Forward, 2015).

The main characteristics of a Delphi method are based on the anonymity of participants, to eliminate the possibility of persuasive effect of some members of the group (Fischer, 1978); it is a dynamic process, because it occurs in a series of rounds, where the experts can give their opinion more than once. The rounds are repeated until the stability of the answers is obtained (Linstone and Turoff, 2011); results of the statistical analysis done to all the answers are provided to the experts as a feedback, by decision of the investigator (von der Gracht, 2012).

The Delphi process was applied between February and May 2019. The final questionnaire, answered in 2 successive rounds, has a set of 21 statements, divided into 2 dimensions: Mediterranean Diet concept and Mediterranean Diet concept use. 
The answer to each statement, demonstrating the degree of agreement or disagreement of each expert, was based on a Likert scale (1: Totally disagree; 2: Disagree; 3: Indifferent; 4: Agree; 5: Totally agree). It was possible to add comments in each round.

\section{Participants}

The institutions of the follow-up group for the Safeguarding and Promotion of the Mediterranean Diet (Resolução do Conselho de Ministros n. 71/2014, 2014), Competence Centre for the Mediterranean Diet (Resolução do Conselho de Ministros n. ${ }^{\circ}$ 71/2014, 2014) and Council for the Safeguarding and Promotion of the Mediterranean Diet (Despacho n. ${ }^{\circ}$ 1939/2019, 2019), were the basis for the selection of the participants of this study, each one being chosen through their solid experience, expertise, knowledge and understanding of the Mediterranean Diet concept. This selection was also looking for a balance between public, academic and private sector expert's origin.

Participants were contacted by email in order to be invited and to receive details of the procedures to be followed. The conditions of participation and the steps to maintain confidentiality were presented and informed consent was obtained.

All respondents received this information and, responded affirmatively in writing, agreeing to participate in the study under these conditions.

The positive answers obtained in the beginning of the study corresponded to $77.8 \%$. During the process only one expert abandoned it.

The final Delphi panel had 28 experts, with the following distribution: $35.7 \%$ from the public sector, $25 \%$ from the academic sector and $39.3 \%$ from the private sector.

\section{Rounds content}

The first round aimed to evaluate the degree of selfknowledge of each expert about the study dimensions and also collect information that could be used to prepare the second round.

In the Mediterranean Diet concept dimension, a Mediterranean Diet concept map was presented, which was built by the authors of this research, based on a previous collaboration with some experts from the Algarve region-Portugal. The model is based on four pillarsfood, conviviality, food production and lifestyle-representing a cultural model, with impact on areas such as the environment, economy, health and tourism.

In the first round, several inputs were collected from the experts, which allowed for some modifications to the model to be presented in the second round. In the second dimension of this Delphi panel, the objective was to study the trends on the areas of Mediterranean Diet concept use. So, in the first round, the experts were asked in which areas they considered that the Mediterranean Diet would be most used; six areas were identified, very much in line with what the researchers had already theorized, based on the literature and knowledge of them in the field.

The second round questioned them on the agreement or disagreement with the suggested Mediterranean Diet conceptual map (dimension 1) and with the 21 statements about the potential Mediterranean Diet concept use, based on 6 areas: culture, education, environment, health, food industry/distribution and tourism. The information on those questions, with the respective bibliographic support, is listed in Table 1.

Given the high degree of consensus reached in the second round (above 70\%), the experts received the statistical information about the previous round and if their score was not in the mean range panel, they were asked to adjust the value to the mean or maintain it and justify their decision. The lowest score reported in the situation of differences with the mean was score of 2 .

\section{Statistical analysis}

For the statistical analysis, we used the arithmetic mean, the standard deviation (SD) and the coefficient of variation $(\mathrm{CV})$. It was used a quantitative analysis for the study of the quantitative responses and a qualitative for the analysis of the comments supplied by the experts.

The level of consensus, which can be either agreement or disagreement on an answer, is defined as a percentage higher than the mean percentage of the majority opinion, which can be above $50 \%$, according to Saldanha and Gray (Saldanha and Gray, 2002). To test the percentage of expert agreement, the CV was used. In this Delphi model, we used the degree of consensus according to the following scale, based on the suggestion by Mili and Bouhaddane (Mili and Bouhaddane, 2018). All the CV values higher than $30 \%$ should be subject to a new round. The cutoff points used were the same for both rounds.

$\mathrm{CV} \leq 30 \%$ : very high degree of consensus

$30 \%<\mathrm{CV} \leq 50 \%$ : high degree of consensus

$50 \%<\mathrm{CV} \leq 70 \%$ : low degree of consensus

$70 \%<\mathrm{CV} \leq 100 \%$ : very low degree of consensus

To understand the level of agreement of the participants, two statistics of dispersion were designed: SD and the $\mathrm{CV}$ and one central tendency statistic: the mean. 
Table 1: Areas, statements and respective bibliographic support about the potential Mediterranean diet concept use (second round of Delphi process)

Area Question Bibliographic support

Environment

In 2028, one-third of the Portuguese population will associate Mediterranean eating style with a smaller ecological footprint.

In 2028, the Mediterranean Diet will be a vehicle for biodiversity promotion.

In 2028, the Mediterranean Diet will be considered as a model to follow in the fight against food waste.

Culture

Education

Food industry/ distribution
In 2028, there will be a National Plan for the Mediterranean Diet Safeguarding, covering the entire national territory.

In 2028, the preservation of the landscapes that characterize the Mediterranean Diet, will be promoted throughout the country.

In 2028, a network of physical and symbolic locations for Mediterranean cultural identity will be promoted.

In 2028, in the area of education there will be a greater presence of the Mediterranean Diet as an educational tool.

In 2028, all school textbooks will include a complete approach to the Mediterranean Diet, against according to the conceptual model presented in D1.

In 2028, the Mediterranean Diet will be presented in school curricula as an integrated vision into more disciplines than just the natural sciences. In 2028, there will be a fiscal incentive that will allow the food products typical of the

Mediterranean Diet to be cheaper than those considered outside this food standard.

In 2028, one of the trends of communication of food products by the agri-food industry will be the inclusion of the concept of the Mediterranean Diet.
In 2013, the Mediterranean Diet was presented as a food sustainability model (Dernini et al., 2013). In 2016, criteria were established for the evaluation of food sustainability based on the Mediterranean Diet (Donini et al., 2016).

The Mediterranean Diet includes in its definition the indication of a local and seasonal products consumption, since the first references by Ancel

Keys (Keys, 1995; UNESCO, 2013b).

The Mediterranean Diet includes in its UNESCO definition the indication of a frugal food consumption (only what is necessary), with cooking diversity and with culinary preparations that invite to a varied and integral food use (UNESCO, 2013b).

The current Mediterranean Diet Safeguard Plan $2018-21$ is only for the Algarve region (Comunidade Representativa de Tavira, 2018). The current Mediterranean Diet Safeguard Plan $2018-21$ provides activities to characterize and preserve the cultural landscape of the

Mediterranean Diet in the Algarve region (Comunidade Representativa de Tavira, 2018). Currently, there are institutions such as the Mediterranean Diet Museum (Tavira), Bread Museum (Pão), Olive Oil Museum (Museu do Azeite), among others, but they are not included in a network throughout the country.

Currently, the Mediterranean Diet is presented in school textbooks as a health promoter food model.

A study from 2016 on school textbooks revealed that the Mediterranean Diet component most commonly was food, and other aspects such as culture, history, economy etc. are not significantly emphasized (Correia, 2016).

Currently, the Mediterranean Diet is presented in school textbooks essentially in the Science component.

Currently, there are taxes applied to foods with lower nutritional value, such as soft drinks.

In 2019, the main trends in product communication are based on sustainability, at the level of environmentally friendly packaging, more natural products and from more sustainable production, with a deviation from the artificial (data provided by PortugalFoods). 
Table 1: (Continued)

\begin{tabular}{c} 
Area Question \\
\hline $\begin{array}{c}\text { In } 2028,50 \% \text { of the large distribution chains will } \\
\text { use the concept of Mediterranean Diet for the } \\
\text { communication of their products and services. }\end{array}$
\end{tabular}

Health

Tourism

$$
\mathrm{CV}=\frac{\sigma}{\bar{\alpha}} * 100
$$

The consensus is reached in this research when the $\mathrm{CV}$ - which is the ratio between the SD and the mean, is less than a predefined result-30\%. In opposite, the statements with less consensus was included in the next round for the expert's re-evaluation.
Bibliographic support

Currently, only one distribution company systematically uses the Mediterranean Diet concept in its food products and services communication. Currently, there are five large distribution companies in Portugal that represent at least $70 \%$ of the national market (data provided by Portuguese

Association of Distribution Companies).

In 2013, half of the Portuguese were uninformed of what the Mediterranean Diet is, according to

data from the Portuguese Cardiology Foundation and GFK. In 2017, 18\% of the Portuguese had high adherence to the Mediterranean Diet, according to the National Food and Physical

Activity Survey (Lopes et al., 2017).

Currently, the index in which there is a greater analysis of food and nutritional components and lifestyle, analyzes in a proportion of 22 to $6 \mathrm{com}$ ponents, respectively (Sotos-Prieto et al., 2015; Real et al., 2020).

Currently, the Portuguese food guide already includes guidelines about the Mediterranean Diet-Mediterranean Food Wheel (DGS, 2016). There is no data to report the current number of units that incorporate these principles, but it is estimated that it is less than $1 \%$. In 2017 , Pordata reported the existence of 5840 tourist accommodations in Portugal (Pordata).

There is currently no recognized seal attesting to the use of the Mediterranean Diet concept. In Spain, a seal is awarded to restaurants that use the Mediterranean Diet concept and join a network recognized by the Mediterranean Diet Foundation (Fundación Dieta Mediterranea).

Nowadays, there is a tourist offer within the scope of gastronomic routes, thematic visits to the harvest, fruit picking, olive oil, festivities associated with collective celebrations, but without reference to the Mediterranean experience.

In 2017, there were 230 agro-tourism units in Portugal, representing an increase of 94 units since 2007, according to Pordata data (Pordata). tence was checked for changes in the relative $\mathrm{CV}$ between successive rounds, as suggested by Dajani et al. (Dajani et al., 1979). From the first round to the second one, we do not found substantial differences in the CV. The majority of items was displaying a change in CV lower than $15 \%$, which are in accordance with the stability criterion suggested by Dajani 


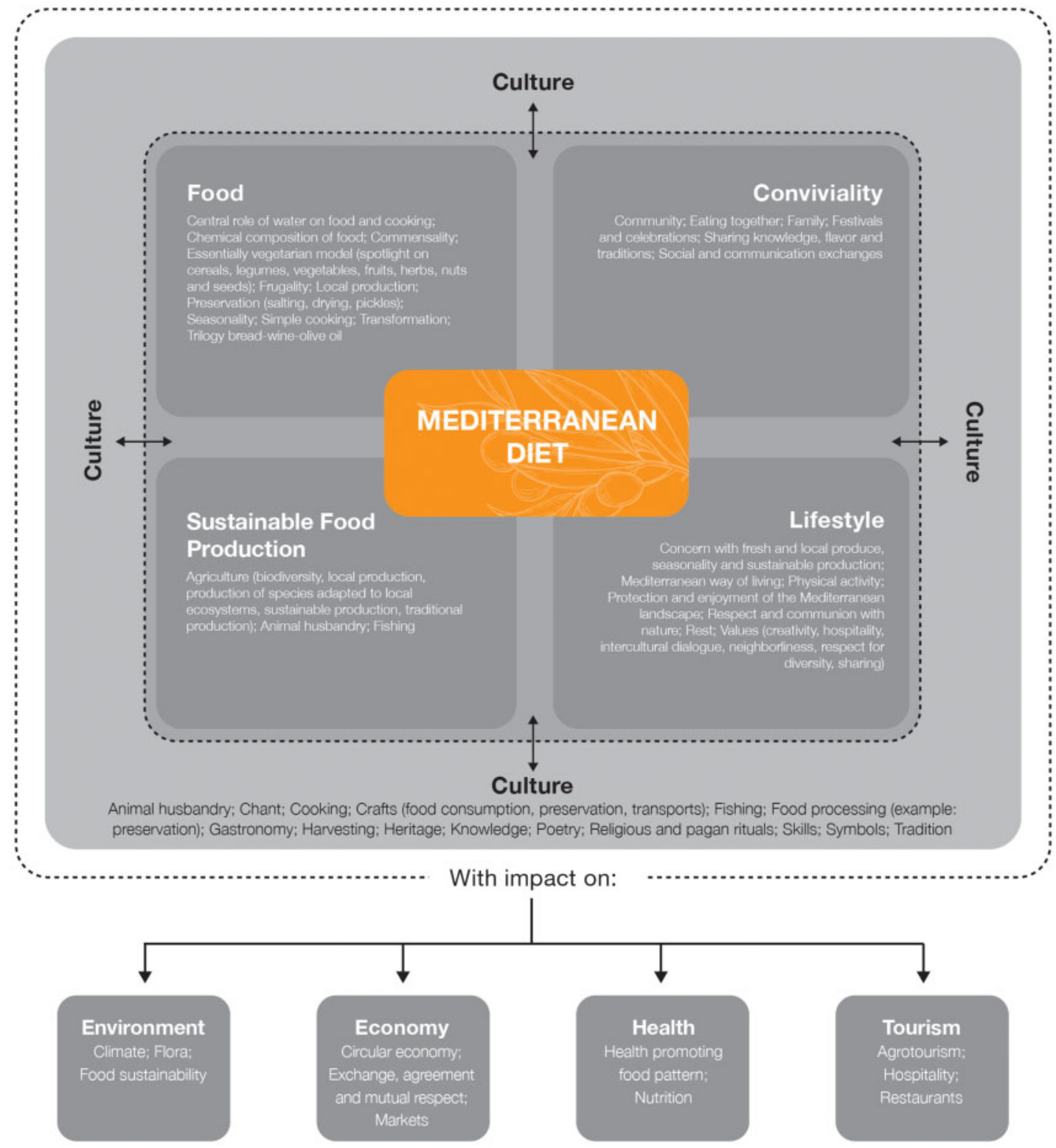

Fig. 1: Mediterranean Diet conceptual map obtained from the consensus in the Delphi. Global analysis suggestion: the model was based on four pillars-food, conviviality, food sustainable production and lifestyle-representing a cultural model, with impact on areas such as the environment, economy, health and tourism. All this involvement can lead to the development of strategies and/ or policies that safeguard and promote the Mediterranean Diet.

et al. (Dajani et al., 1979) and Scheibe et al. (Scheibe et al., 1975) allowing to finish the Delphi process.

\section{RESULTS}

Figure 1 shows the Mediterranean Diet conceptual model obtained from $73.8 \%$ of consensus in the Delphi panel. This model incorporated some of the experts' suggestions from the first round, being the result of a complex process of literature analysis and perceptions of professionals from the Mediterranean Diet area. The model was based on four pillars-food, conviviality, food sustainable production and lifestyle-representing a cultural model, with impact on areas such as the environment, economy, 
Table 2: Mediterranean Diet Delphi results of two rounds in the research dimensions: 1—Mediterranean Diet concept map; 2-Mediterranean Diet use areas

\begin{tabular}{|c|c|c|c|c|c|c|c|c|}
\hline \multirow[t]{2}{*}{ Dimension } & \multirow[t]{2}{*}{ Area } & \multirow[t]{2}{*}{ Statement } & \multicolumn{3}{|c|}{2 nd round } & \multicolumn{3}{|c|}{3 nd round } \\
\hline & & & Mean & SD & $\mathrm{CV}$ & Mean & SD & $\mathrm{CV}$ \\
\hline 1 & Conceptual Map & $\begin{array}{l}\text { In } 2028 \text {, the Mediterranean Diet conceptual } \\
\text { model, graphically presented, will be recog- } \\
\text { nized as one of the most appropriate ways of } \\
\text { defining the Mediterranean Diet. }\end{array}$ & 3.79 & 1.07 & 28.23 & 3.85 & 1.01 & 26.23 \\
\hline \multirow[t]{13}{*}{2} & Use areas & $\begin{array}{l}\text { Culture, education, environment, health, indus- } \\
\text { try/distribution and tourism will be the main } \\
\text { areas where the concept of the Mediterranean } \\
\text { Diet will be used in } 2028 \text {. }\end{array}$ & 4.18 & 0.72 & 17.22 & 4.18 & 0.72 & 17.22 \\
\hline & Environment & $\begin{array}{l}\text { In } 2028 \text {, one-third of the Portuguese population } \\
\text { will associate Mediterranean eating with a } \\
\text { smaller ecological footprint. }\end{array}$ & 4.07 & 0.77 & 18.92 & 4.15 & 0.65 & 15.66 \\
\hline & & $\begin{array}{l}\text { In } 2028 \text {, the Mediterranean Diet will be a vehi- } \\
\text { cle for biodiversity promotion. }\end{array}$ & 4.11 & 0.74 & 18.00 & 4.11 & 0.74 & 18.00 \\
\hline & & $\begin{array}{l}\text { In } 2028 \text {, the Mediterranean Diet will be consid- } \\
\text { ered as a model to follow in the fight against } \\
\text { food waste. }\end{array}$ & 3.79 & 0.79 & 20.84 & 3.85 & 0.70 & 18.18 \\
\hline & Culture & $\begin{array}{l}\text { In } 2028 \text {, there will be a National Plan for the } \\
\text { Mediterranean Diet Safeguarding covering } \\
\text { the entire national territory. }\end{array}$ & 4.07 & 0.86 & 21.13 & 4.07 & 0.86 & 21.13 \\
\hline & & $\begin{array}{l}\text { In } 2028 \text {, it will be promoted a preservation of } \\
\text { the landscapes that characterize the } \\
\text { Mediterranean Diet, throughout the country. }\end{array}$ & 3.75 & 0.93 & 24.80 & 3.75 & 0.93 & 24.80 \\
\hline & & $\begin{array}{l}\text { In } 2028 \text {, a network of physical and symbolic } \\
\text { locations for Mediterranean cultural identity } \\
\text { will be promoted. }\end{array}$ & 4.00 & 0.72 & 18.00 & 4.00 & 0.72 & 18.00 \\
\hline & Education & $\begin{array}{l}\text { In } 2028 \text {, in the area of education there will be a } \\
\text { greater presence of the Mediterranean Diet as } \\
\text { an educational tool. }\end{array}$ & 4.36 & 0.73 & 16.74 & 4.36 & 0.73 & 16.74 \\
\hline & & $\begin{array}{l}\text { In } 2028 \text {, all scholar textbooks will include a } \\
\text { complete approach to the Mediterranean } \\
\text { Diet, against the conceptual model presented } \\
\text { in D1. }\end{array}$ & 4.14 & 0.85 & 20.53 & 4.14 & 0.85 & 20.53 \\
\hline & & $\begin{array}{l}\text { In } 2028 \text {, the Mediterranean Diet will be pre- } \\
\text { sented in school curricula as an integrated vi- } \\
\text { sion into more disciplines than just the } \\
\text { natural sciences. }\end{array}$ & 4.07 & 0.81 & 19.90 & 4.07 & 0.81 & 19.90 \\
\hline & $\begin{array}{r}\text { Food Industry/ } \\
\text { Distribution }\end{array}$ & $\begin{array}{l}\text { In } 2028 \text {, there will be a fiscal incentive that will } \\
\text { allow the food products typical of the } \\
\text { Mediterranean Diet to be cheaper than those } \\
\text { considered outside this food standard. }\end{array}$ & 3.32 & 1.02 & 30.72 & 3.42 & 0.95 & 27.78 \\
\hline & & $\begin{array}{l}\text { In } 2028 \text {, one of the trends of communication of } \\
\text { food products by the agri-food industry will } \\
\text { be the inclusion of the concept of } \\
\text { Mediterranean Diet. }\end{array}$ & 4.04 & 0.92 & 22.77 & 4.18 & 0.72 & 17.22 \\
\hline & & $\begin{array}{l}\text { In } 2028,50 \% \text { of the large distribution chains } \\
\text { will use the concept of Mediterranean Diet } \\
\text { for the communication of their products and } \\
\text { services. }\end{array}$ & 3.68 & 1.02 & 27.72 & 3.74 & 0.97 & 25.94 \\
\hline
\end{tabular}


Table 2: (Continued)

\begin{tabular}{|c|c|c|c|c|c|c|c|c|}
\hline \multirow[t]{2}{*}{ Dimension } & \multirow[t]{2}{*}{ Area } & \multirow[t]{2}{*}{ Statement } & \multicolumn{3}{|c|}{2 nd round } & \multicolumn{3}{|c|}{3 nd round } \\
\hline & & & Mean & SD & $\mathrm{CV}$ & Mean & SD & $\mathrm{CV}$ \\
\hline \multirow{3}{*}{\multicolumn{2}{|c|}{ Health }} & $\begin{array}{l}\text { In } 2028,25 \% \text { of the Portuguese will understand } \\
\text { the relationship between the Mediterranean } \\
\text { Diet and health and will use it to improve } \\
\text { their lives. }\end{array}$ & 3.82 & 0.77 & 20.16 & 3.82 & 0.77 & 20.16 \\
\hline & & $\begin{array}{l}\text { In } 2028 \text {, there will be an index that assesses ad- } \\
\text { herence to the Mediterranean Diet with equal } \\
\text { expression of food components and lifestyle. }\end{array}$ & 3.79 & 0.79 & 20.84 & 3.79 & 0.79 & 20.84 \\
\hline & & $\begin{array}{l}\text { In } 2028 \text {, health professionals will systematically } \\
\text { include the concept of Mediterranean Diet in } \\
\text { their recommendations (food, environmental } \\
\text { etc.). }\end{array}$ & 4.11 & 0.69 & 16.79 & 4.11 & 0.69 & 16.79 \\
\hline \multirow{4}{*}{\multicolumn{2}{|c|}{ Tourism }} & $\begin{array}{l}\text { In } 2028,5 \% \text { of Portuguese tourist hotel accom- } \\
\text { modations will seek to incorporate the con- } \\
\text { cepts of Mediterranean Diet into the } \\
\text { provision of space and services, such as } \\
\text { meals. }\end{array}$ & 4.07 & 0.77 & 18.92 & 4.22 & 0.50 & 11.85 \\
\hline & & $\begin{array}{l}\text { In } 2028 \text {, there will be a quality seal that certifies } \\
\text { the use of the concept of Mediterranean Diet } \\
\text { for Portuguese restaurants. }\end{array}$ & 3.86 & 0.80 & 20.73 & 3.86 & 0.80 & 20.73 \\
\hline & & $\begin{array}{l}\text { In } 2028,10 \% \text { of the new tourist offerings will } \\
\text { position themselves and communicate their } \\
\text { insertion in the concept of Mediterranean } \\
\text { Diet, together with a model of sustainable } \\
\text { tourism and/or a vehicle of conviviality } \\
\text { through the promotion of festivities and } \\
\text { traditions. }\end{array}$ & 4.00 & 0.82 & 20.50 & 4.07 & 0.72 & 17.69 \\
\hline & & $\begin{array}{l}\text { In } 2028 \text {, there will be more than } 500 \text { agro-tour- } \\
\text { ism units in Portugal. }\end{array}$ & 3.82 & 0.72 & 18.85 & 3.89 & 0.63 & 16.20 \\
\hline
\end{tabular}

Mean values based on the statement scores (Likert scale: 1-totally disagree; 2-disagree; 3-indifferent; 4-agree; 5-totally agree). CV scale: CV $\leq 30$ : Very high degree of consensus; $30<\mathrm{CV} \leq 50$ : High degree of consensus; $50<\mathrm{CV} \leq 70$ : Low degree of consensus; $70<\mathrm{CV} \leq 100$ : Very low degree of consensus.

$\mathrm{SD}$, standard deviation; CV, coefficient of variation.

health and tourism. Each area is associated with a set of characteristics that support their definition.

The results of the Delphi method application are presented in Table 2 with the illustration of the two rounds.

The percentage of agreement varied between 72.2 and $88.2 \%$, which represents a very high degree of consensus.

Figure 2 presents an ordered list of trends for 2028 by agreement percentage. The five trends with the highest agreement are from the areas of tourism, environment, education and health.

\section{DISCUSSION OF RESULTS}

The literature presents a considerable variation in the recommendation of the number of participants in a Delphi panel. However, references often pointed to a minimum of eight participants (Sourani and Sohail,
2015). Therefore, this study's Delphi panel had an acceptable number of experts.

Concerning the number of rounds utilized, it should be emphasized that it would not have been necessary to advance to the last one, since the $\mathrm{CV}$ already had values framed by high consensus. However, the researchers considered more advantageous for the study, to contact all the experts with answer scores different from the mean to adjust the score to the mean or maintain the score.

In this study, we presented an innovative way to define the Mediterranean Diet, through a conceptual map. To our best knowledge the Mediterranean Diet has never been presented this way. Thus, the Mediterranean Diet conceptual map explored in this research contributes to clarify the currently literature on the definition of Mediterranean Diet. An image or scheme always makes transmitting a message easier, especially to children. It is 


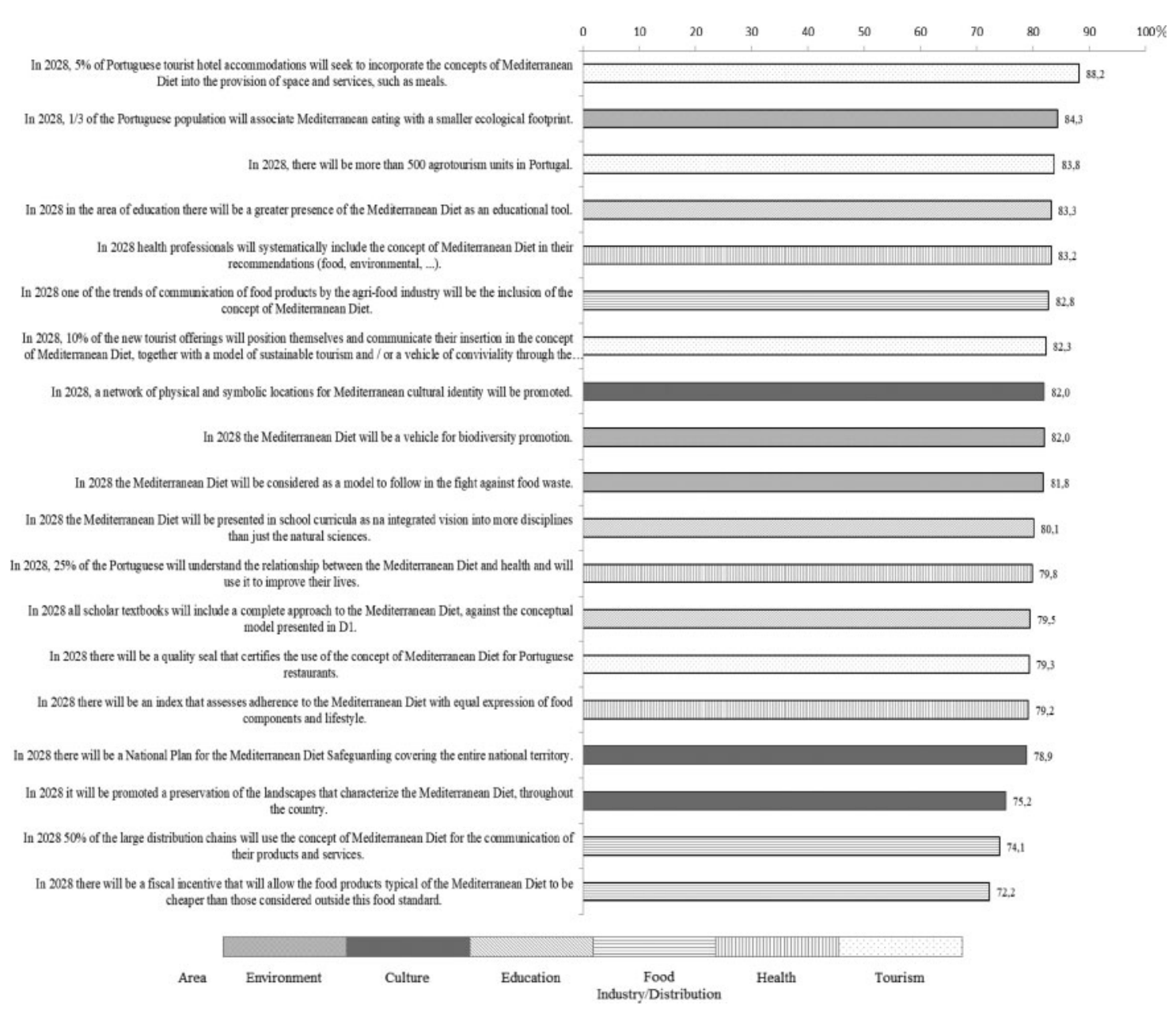

Fig. 2: Ordered list of Mediterranean Diet use trends for 2028 by agreement percentage.

like the example of the Mediterranean Diet pyramids, which can easily transmit various aspects about the Mediterranean Diet definition. However, some of the experts consider that this conceptual model may be limited and does not include all the Mediterranean Diet aspects, it is not in the correct position or does not fit with some realities. Therefore, the agreement percentage was one of the lowest, but still high $(73.9 \%)$, which allows us to state that it is a tool with a high level of agreement to be used in the future. However, this is not a closed document, because it can be improved over time and we think that this model is sufficiently dynamic to allow different approaches by regions or countries. Although this model was developed by Portuguese experts, the researchers consider that it represents the cross-sectional definition of the Mediterranean Diet and, for example, not only a Portuguese interpretation.
This study identified culture, education, environment, health, food industry/distribution and tourism as the future trends to Mediterranean Diet use areas.

These are not currently the areas with the highest impact on the Mediterranean Diet, as shown in the consensual conceptual map, but were the areas which the experts estimated will be the future trends.

Even though all the items in each area showed a high agreement percentage, it was possible to verify that Tourism and Environment were the areas where the highest percentage of agreement was obtained. Regarding the first 10 trends identified, all the statements of environment area and almost all the tourism area are in this shortlist. A possible explanation for this is that these two areas have most marked the agenda of the country and the Mediterranean Diet can fit into it very well. Thus, more than a trend it could be an 
opportunity for the Mediterranean Diet to increase its notoriety and adherence by the population. Queiroz stated in a book 'The Mediterranean Diet-Ancient Heritage for Humanity' that the Mediterranean Diet contributed to the rehabilitation of ancestral practices and techniques, adapting them to the current reality, such as production practices, preservation of biodiversity species, healthy lifestyles, user-friendliness and preservation of local cultures, promotion of local economies and cultural and nature tourism. He also referred that the Mediterranean Diet would play an important role in the coming years in bringing the peoples of the Mediterranean closer together and in preserving the ancient heritages (Queiroz, 2015).

There are several recommendations in most of the official documents for the preservation of the environment. On the other hand, the Mediterranean Diet is frequently associated with food sustainability, as an example of a sustainable diet (Dernini et al., 2013; Dernini and Berry, 2015; Donini et al., 2016). However, is not easy to measure the indicators for this association, therefore, there is not enough evidence in this area to demonstrates this relationship. So, this can be an opportunity for the promotion of the Mediterranean Diet.

Concerning tourism, it is an expanding area in the Mediterranean and in particular in Portugal. Recent studies carried out in the Mediterranean area show that tourism can promote the Intangible Cultural Heritage of the regions, with advantages for the various players such as tourists, hoteliers, local communities and the tourism industry (Sotiriadis, 2017). However, it is also important to monitor this tourism growth because it could change the resident population's eating habits when the gastronomic offer is adapted to tourists' preferences (Rodríguez-Mireles et al., 2018). Tourists also want to be influenced by the local food culture when on holidays (Bessiere and Tibere, 2013; Rodríguez-Mireles et al., 2018), so it can be an opportunity to promote the Mediterranean Diet in Portugal and in the Mediterranean countries.

Education is also an important area to explore in the Mediterranean Diet. Some previous studies showed that education can be one of the biggest solutions in the promotion and safeguard of the Mediterranean Diet (Dernini et al., 2017). Therefore, these educational trends can be the beginning of that work. It is also known that countries with higher educational level are guiding their public policies to food education and healthy lifestyles, beginning in schools, with the Mediterranean Diet as a reference (Queiroz, 2015). Dernini had already advanced a suggestion in 2016 of an educational schematic model on the Mediterranean Diet as a sustainable diet, in which he argued that teaching on the subject should be inserted into the school curricula of the Mediterranean countries in addition to other measures, which also include education for families and the rest of the community where students are inserted (Dernini et al., 2017). Other previous study that we made reported also the perception of some professionals about the importance of Mediterranean Diet concept education to students. However, they also defended the organization of some training actions for different professional sectors, in order to promote awareness on Mediterranean Diet topics such as seasonality, friendliness, family; and some training actions for health professionals, such as nutritionists, doctors, nurses etc. (Real and Graça, 2019). It is important that health professionals and those of the agri-food sector realize the Mediterranean Diet concept in order to be able to guide their customers, products, services or initiatives in this context.

Culture and food industry/distribution were the areas with lower agreement percentage. Since the Mediterranean Diet is a cultural model, it is important to promote more initiatives to improve this area and its recognition by the population. The food industry/distribution is also an important area because it is one of the closest areas to the population, so it has to be monitored. It can be an excellent partner in the promotion of the Mediterranean Diet, so it can be considered in the promotion initiatives, but it can also be an incoherent vehicle of information, if it does not make correct use of the Mediterranean Diet concept. Previous research by the authors of this paper showed that, regarding abusive use of the Mediterranean Diet concept, it was mainly related to the food industry, gastronomy and food advertising, motivated by the commercial vision (Real and Graça, 2019). Regarding the actual food trends, we were looking for a greater agreement in the area of food industry/distribution, because the Mediterranean Diet can join several characteristics of their trends. Maybe it is also important to define a 'Mediterranean food/product', this approach has been pointed out by some experts in the area of the Mediterranean Diet under the International Task Force on the Mediterranean Diet (Serra-Majem et al., 2004), to promote the dissemination on the food industry/distribution. Our previous results appointed the interest of the certification possibility, the regulation of the practices of using the Mediterranean Diet concept and a seal that guarantees the quality of the products, in order to preserve the Mediterranean Diet concept and avoid its abuse (Real and Graça, 2019). The recommendations of the EATLancet Commission on healthy diets from sustainable food systems highlighted several issues that are common 
to the trends that we found in this study, such as environment, education, food industry/distribution or health (Willett et al., 2019). Thus, according these recommendations, the Mediterranean food pattern can be a good option to achieve the goals of EAT-Lancet Commission. However, it is fundamental to have an integrated vision about the Mediterranean Diet. We cannot analyze the areas in isolation, but as a whole, in order to guarantee a more efficient promotion and safeguard of the Mediterranean Diet. Elling Bere argued that the regional promotion of the Mediterranean Diet, specific to each region or country, will be more advantageous than the world-wide one, in order to maintain food variety, diversity and cultural heritages, as well as environmental protection (Bere and Brug, 2010). Portugal currently has a Mediterranean Diet Safeguard Plan for the Algarve region, in the south of Portugal, and it is important to plan the safeguard of other regions, to prevent the concept deterioration or to promote its existence.

This trends study can contribute with valid information to the development of the next Safeguard Plans, where some important issues need to be considered for a better promotion and safeguard of this concept, and its potential abusive use.

In terms of limitations of this study, we can indicate the selection of experts only from a Portuguese context. For the exploration of trends in the Mediterranean Diet use in Portugal, it was the best selection. However, for the analysis of the Mediterranean Diet concept map, it can be a limitation. It could be relevant to move forward to other countries and extend the discussion about the conceptual model presented to other experts, because we want that this tool to be transversal and not limited to the Portuguese reality. This study presents some trends on the Mediterranean Diet in Portugal. So, another limitation could be the question: are the experts a representative sample of the national thought on the matter? If the panel of experts was changed, the results could have been different, but we believe that the Delphi panel had the best experts for this study, therefore, the trends expressed would be a close fit to the reality.

The trends are for Portugal, but considering the similarities with other Mediterranean countries, these data may be common to other regions and can therefore inspire other countries.

\section{CONCLUSIONS}

This research presents an innovative model to define the Mediterranean Diet. There was also a high consensus to recognize this model as one of the best ways to present the Mediterranean Diet definition, in 2028. For the first time, it was also possible to explore the future trends of Mediterranean Diet concept use namely in the areas of culture, education, environment, health, food industry/ distribution and tourism, where the tourism and environment had the higher agreement percentage. This can be a new approach for the development of initiatives to limit an eventual inappropriate use of the Mediterranean Diet concept. This information can help also in the elaboration of future Mediterranean Diet Safeguard Plans.

\section{CONFLICT OF INTEREST STATEMENT}

None declared.

\section{REFERENCES}

Bere, E. and Brug, J. (2010) Is the term 'Mediterranean diet' a misnomer? Public Health Nutrition, 13, 2127-2129.

Bessiere, J. and Tibere, L. (2013) Traditional food and tourism: French tourist experience and food heritage in rural spaces. Journal of the Science of Food and Agriculture, 93, 3420-3425.

Centro de Competências para a Dieta Mediterrânica (2018). http://www.dietamediterranica.net/?q=es/node/755 (last accessed 30 January 2019).

Comunidade Representativa deTavira (2018) Salvaguarda Dieta Mediterrânica - Plano de Atividades 2018-2021, para a região do Algarve. http://www.dietamediterranica.net/sites/ default/files/CRDM_PA_2018_2021_Algarve_v1.pdf (last accessed 30 January 2019).

Correia, V. B. (2016) A dieta Mediterrânica como ferramenta pedagógica em contexto escolar (Master), Universidade do Porto, Faculdade de Ciências da Nutrição e Alimentação da Universidade do Porto. http://catalogo.up.pt:80/F/?func= direct\&doc_number $=000839091 \&$ local_base $=$ CNAUP (last accessed 30 January 2019).

Dajani, J. S., Sincoff, M. Z. and Talley, W. K. (1979) Stability and agreement criteria for the termination of Delphi studies. Technological Forecasting and Social Change, 13, 83-90.

Dernini, S. and Berry, E. M. (2015) Mediterranean diet: from a healthy diet to a sustainable dietary pattern. Frontiers in Nutrition, 2, 15.

Dernini, S., Berry, E. M., Serra-Majem, L., La Vecchia, C., Capone, R., Medina, F. X. et al (2017) Med Diet 4.0: the Mediterranean diet with four sustainable benefits. Public Health Nutrition, 20, 1322-1330.

Dernini, S., Meybeck, A., Burlingame, B., Gitz, V., Lacirignola, C., Debs, P. et al (2013) Developing a methodological approach for assessing the sustainability of diets: the Mediterranean diet as a case study. New Medit, 12, 28-36.

Despacho, n.o 1939/2019. (2019) Determina a criação do Conselho Dinamizador para a Salvaguarda e Promoção da 
Dieta Mediterrânica (CDDM). Diário da República n. ${ }^{\circ}$ 41/2019, Série II de 2019-02-27.

DGS, FCNAUP and DGC. (2016) Roda da Alimentação Mediterrânica: Cartaz da Roda da Alimentação Mediterrânica. https://nutrimento.pt/activeapp/wp-content/ uploads/2016/06/Cartaz-A3-13_med.pdf (last accessed 30 January 2019).

Donini, L. M., Dernini, S., Lairon, D., Serra-Majem, L., Amiot, M.-J., Del Balzo, V. et al (2016) A consensus proposal for nutritional indicators to assess the sustainability of a healthy diet: the mediterranean diet as a case study. Frontiers in Nutrition, 3, 37.

Fischer, R. G. (1978) The Delphi method: a description, review and criticism. The Journal of Academic Librarianship, 4, 64-70.

Fundación Dieta Mediterranea. Sello Restaurantes Mediterraneos. https://restaurantesdietamediterranea.com/ sello-para-restaurantes-mediterraneos/ (last accessed 30 January 2019).

Geist, M. R. (2010) Using the Delphi method to engage stakeholders: a comparison of two studies. Evaluation and Program Planning, 33, 147-154.

Hsu, C.-C. and Sandford, B. A. (2007) The Delphi technique: making sense of consensus practical assessment. Research \& Evaluation, 12, 10.

James, D. and Warren-Forward, H. (2015) Research methods for formal consensus development. Nurse Researcher, 22, 35-40.

Keys, A. (1995) Mediterranean diet and public health: personal reflections. The American Journal of Clinical Nutrition, 61, 1321s-1323s.

Linstone, H. and Turoff, M. (1975) Introduction. In Linstone, H. and Turoff, M. (eds), The Delphi Method Techniques and Application. Addison-Wesley, Reading, pp.3-12.

Linstone, H. and Turoff, M. (2011) Delphi: a brief look backward and forward. Technological Forecasting and Social Change, 78, 1712-1719.

Lopes, C., Torres, D., Oliveira, A., Severo, M., Alarcão, V., Guiomar, S. et al (2017) Inquérito Alimentar Nacional e de Atividade Física, IAN-AF 2015-2016: Relatório de Resultados. www.ian-af.up.pt (last accessed 30 January 2019).

Mili, S. and Bouhaddane, M. (2018) A Forecast of Internationalization Strategies for the Spanish Olive Oil Value Chain. Proceedings in System Dynamics and Innovation in Food Networks 2018, pp. 1 - 27.

Museu do Azeite. http://www.museudoazeite.com/\#firstPage (last accessed 30 January 2019).

Museu do Pao. http://www.museudopao.pt/ (last accessed 30 January 2019).

Pordata. Alojamentos turísticos: total e por tipo de estabelecimento. https://www.pordata.pt/Portugal/Alojamentos+tur $\%$ c3\% adsticos +total + e+ por+tipo+de+estabelecimento2562 (last accessed 30 January 2019).
Pordata. Estabelecimentos de turismo de habitação e de turismo no espaço rural: total e por tipo de estabelecimento. https://www. pordata.pt/Portugal/Estabelecimentos+de+turismo+de+habita $\%$ c3 $\%$ a $7 \%$ c3 $\%$ a3o + e+de+turismo + no + espa $\%$ c3\%a7o+ rural+total + e+ por+tipo+de+estabelecimento-2607-217241 (last accessed 30 January 2019).

Queiroz, J (2015) Dieta Mediterrânica, que futuro? In Althum.com (ed), Dieta Mediterrânica. Uma Herança Milenar Para a Humanidade, 2nd edn. Lisboa, p. 255.

Real, H. and Graça, P. (2019) Marcos da História da Dieta Mediterrânica, desde Ancel Keys. Acta Portuguesa de Nutrição, 17, 06-14.

Real, H. and Graça, P. (2019) Perceções de utilização do conceito de Dieta Mediterrânica, potencial utilização indevida e perspetivas a explorar. Revista Española de Comunicación en Salud, 10, 147-159.

Real, H., Queiroz, J. and Graca, P. (2020) Mediterranean food pattern vs. Mediterranean diet: a necessary approach? International Journal of Food Sciences and Nutrition, 71, 1-12.

Resolução do Conselho de Ministros n. ${ }^{\circ}$ 71/2014. (2014). Cria o Grupo de Acompanhamento para a Salvaguarda e Promoção da Dieta Mediterrânica. Diário da República n. ${ }^{\circ}$ 232/2014, Série I de 2014-12-01.

Rodríguez-Mireles, S., López-Valcárcel, B., Serra-Majem, L., Hernández-Yumar, A., Barber-Pérez, P., Pinilla-Domínguez, J. et al (2018) Effect of tourism pressure on the Mediterranean diet pattern. Nutrients, 10, doi: 1338.3390/nu10101338

Saldanha, J. and Gray, R. (2002) The potential for British coastal shipping in a multimodal chain. Maritime Policy o Management, 29, 77-92.

Scheibe, M., Skutsch, M. and Schafer, J. (1975) Experiments in Delphi methodology. In Linstone, H. A. and Turoff, M. (eds), The Delphi Method: Techniques and Applications. Addison-Wesley, Reading, pp. 267-287.

Serra-Majem, L., Trichopoulou, A., de la Cruz, J. N., Cervera, P., Álvarez, A. G., La Vecchia, C. et al (2004) Does the definition of the Mediterranean diet need to be updated? Public Health Nutrition, 7, 927-929.

Sotiriadis, M. (2017) Pairing intangible cultural heritage with tourism: the case of Mediterranean diet. Euromed Journal of Business, 12, 269-284.

Sotos-Prieto, M., Moreno-Franco, B., Ordovás, J. M., León, M., Casasnovas, J. A. and Peñalvo, J. L. (2015) Design and development of an instrument to measure overall lifestyle habits for epidemiological research: the Mediterranean Lifestyle (MEDLIFE) index. Public Health Nutrition, 18, 959-967.

Sourani, A. and Sohail, M. (2015) The Delphi method: review and use in construction management research. International Journal of Construction Education and Research, 11, 54-76.

Tavira M. M. d. Exposição "Dieta Mediterrânica-Património Cultural Milenar”. http://dietamediterranica.net/?q=pt/ node/164 (last accessed 30 January 2019). 
UNESCO. What is Intangible Cultural Heritage? https://ich. unesco.org/en/what-is-intangible-heritage-00003 (last accessed 30 January 2019).

UNESCO (2013a) ITH/13/8.COM/Decisions. https://www.goo gle.pt/url? $\mathrm{sa}=\mathrm{t} \& \mathrm{rct}=\mathrm{j} \& \mathrm{q}=\&$ esrc $=\mathrm{s} \&$ source $=\mathrm{web} \& \mathrm{~cd}=3 \&$ ved=2ahUKEwjn6pyO5aXmAhVOXhoKHU8CCNgQFjAC egQIBRAJ\&url=https $\% 3 \mathrm{~A} \% 2 \mathrm{~F} \% 2 \mathrm{Fich}$.unesco.org $\% 2 \mathrm{Fdoc}$ $\% 2$ Frc \%2FITH-13-8.COM-Decisions-EN.doc\&usg=AOv Vaw25MidTHHG32w0U8oDKe6xd (last accessed 30 January 2019).

UNESCO (2013b) Mediterranean Diet. http://www.unesco.org/ culture/ich/en/RL/mediterranean-diet-00884 (last accessed 30 January 2019).

UNESCO (2018) Diretrizes Operativas para a Aplicação da Convenção para a Salvaguarda do Património Cultural Imaterial (versão 2018). https://ich.unesco.org/en/in-otherlanguages-01010 (last accessed 30 January 2019).
United Nations (2015) Sustainable Development Goals. https:// sustainabledevelopment.un.org/?menu=1300 (last accessed 30 January 2019).

Vilarnau, C., Stracker, D. M., Funtikov, A., da Silva, R., Estruch, R. and Bach-Faig, A. (2019) Worldwide adherence to Mediterranean diet between 1960 and 2011. European Journal of Clinical Nutrition, 72, 83-91.

von der Gracht, H. A. (2012) Consensus measurement in Delphi studies: review and implications for future quality assurance. Technological Forecasting and Social Change, 79, 1525-1536.

Willett, W., Rockström, J., Loken, B., Springmann, M., Lang, T., Vermeulen, S. et al (2019) Food in the Anthropocene: the EAT-Lancet Commission on healthy diets from sustainable food systems. Lancet, 393, 447-492. 